\title{
Physics in Yugoslavia
}

\section{R. Blinc, Josef Stefan Institute N. Cindro, Rudjer Boskovic Institute}

The development of large scale organized scientific activities in the field of physics in Yugoslavia was started during the early post-war years. In 1947, the Federal Government established the first large research centre at Vinca near Belgrade, now the Boris Kidric* Institute (BKI) of Nuclear Sciences. It was followed in 1949 by the Jozef Stefan** Institute (JSI) in Ljubljana, and a year later by the Rudjer Boskovic*** Institute (RBI) in Zagreb. During the first ten years or so of their existence these centres devoted most of their activities to research on nuclear phenomena and the uses of nuclear energy. Later on, with increasing needs for modern technology in every domain of the country's economic developments, the shift from the strict nuclear programme towards other scientific fields became unavoidable. At present, the three research centres provide an important basis for lively scientific activity in physics, as well as in other pure sciences, thanks to the large concentration of equipment and competent scientific staff.

The part played by academic science has received much attention with the general liberalization of the country's science policy during the past decade. This circumstance has evidently encouraged the foundation of research institutes affiliated to the universities, such as the Institutes of Physics in Belgrade and in Zagreb,

\footnotetext{
* Boris Kidric (1912-1953) : Yugoslav politician, in charge of national planning in the post-war period, who worked for the
} establishment of the nuclear institutes.

*. Jozef Stefan (1835-1893): Slovenian physicist working in Vienna. His most important scientific contributions are those concerning the kinetic theory of gases, their diffusion and heat conductivity. He originated the law of the total radiation from a black body (Stefan-Boltzmann law).

** Rudjer Josip Boskovic (1711-1787): Croatian mathematician, physicist and astronomer who worked in Italy and France. His main contributions are in applied mathematics, geodesy, mechanics and the molecular theory of matter where he anticipated the concept of the atom as a centre of force. and similar institutions in Ljubljana, Sarajevo and Skoplje. These institutes have maintained a rather independent scientific activity not strictly related to teaching purposes. On the other hand, the fertile co-operation between the universities and the three large research centres concerning both research and educational activities clearly remains the vital force of the advancement of physical sciences in Yugoslavia.

A rather small proportion of scientific research in physics is carried out by various other research institutes and some of the industrial laboratories. It appears that industry has been largely relying on imported technological knowledge, although there have recently been some successful industrial applications of modern scientific methods, for example in the development of gas lasers.

The Federal Council for the Co-ordination of Scientific Activities was the highest body responsible for the advancement of physical sciences. Nearly all financial support for physics research was supplied through the Federal Fund for Scientific Research, the Federal Nuclear Energy Commission and funds of the republics. Recent reorganization put much greater emphasis on the allocations by the republics, to which nearly all federal funds have been passed. Contracts with applicants are currently drawn up on the basis of criteria stressing scientific merit of the projects, the applicant's past successes and his international reputation.

Physicists in this country can become members of a number of professional organizations. The central organization is the Association of Yugoslav Mathematicians, Physicists and Astronomers, which has many members among those professionally engaged in scientific research in various fields of physics. The Physics Division of the Association issues the international scientific journal "Fizika" (Physics) which, since 1970, has the status of a Europhysics Journal.

During little more than two decades of lively scientific activity, Yugoslav physicists contributed an appreciable share of scientific information to the physics community as a whole. To foster international co-operation they have organized a number of symposia and conferences. Hundreds of young physicists from many countries have been welcome to participate in summerschools and seminars; those held in Herceg Novi have become particularly well known.

Soon after the war Yugoslavia had started extensive work in the field of nuclear energy, and the number of nuclear scientists in Yugoslavia, practically zero in the early post-war years, rose rapidly during the period from 1950 and 1960 . It reached a maximum around 1965 and has been tending to decrease slightly since then. The estimated scientific staff working at present in the field of nuclear physics in Yugoslavia is about 200 (M. Sc. and higher). This still represents a very valuable potential even though nowadays it is working on obsolescent equipment.

The nuclear hardware in Yugoslavia dates mostly from the late fifties and early sixties. The major pieces of equipment comprise :

- a $30 \mathrm{MeV}$ betatron for electron acceleration and gamma-ray production (JSI, Ljubljana),

- a $2.2 \mathrm{MeV}$ proton Van de Graaff accelerator (JSI, Ljubljana).

- a $16 \mathrm{MeV}$ deuteron cyclotron (RBI, Zagreb),

- a $1.2 \mathrm{MeV}$ Cockcroft-Walton accelerator (BKI, Vinca),

- a $0.6 \mathrm{MeV}$ proton Van de Graaff accelerator (Institute of Physics, Split).

Several 200 keV Cockcroft-Walton accelerators are in service as neutron generators in the three nuclear institutes. Furthermore, the Boris Kidric Institute at Vinca is the home of several beta spectrometers. Two major research reactors, one 6.5-10 MW, Soviet built, and a $250 \mathrm{~kW}$ TRIGA type reactor are located at Vinca and Ljubljana, respectively. Earlier, a locally built zero-power reactor was put into operation at Vinca. No major piece of equipment has been constructed since 


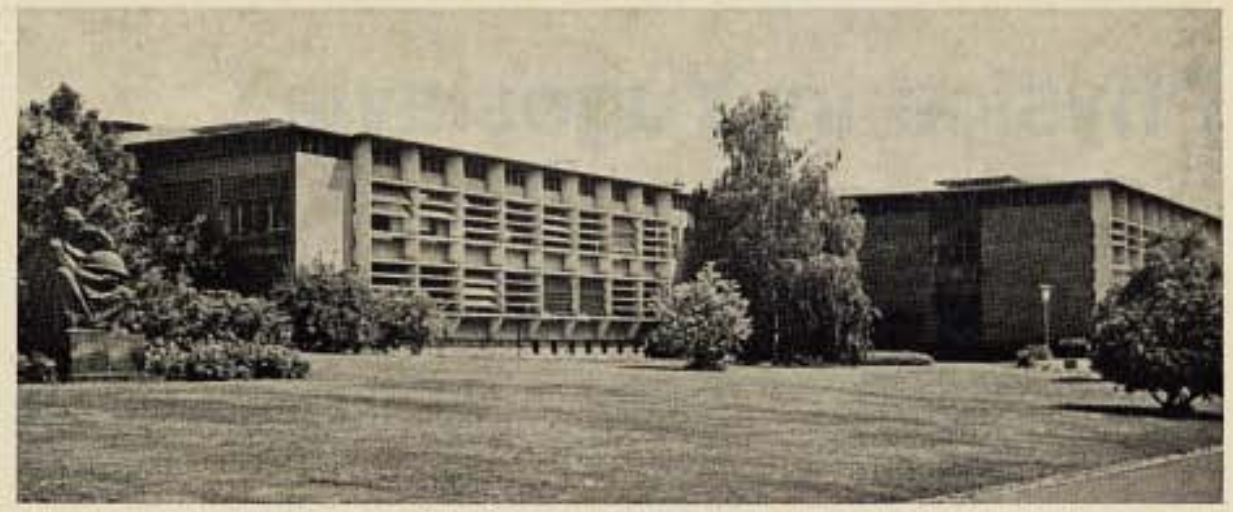

the early sixties. Thus the present outlook of experimental nuclear physics in Yugoslavia is not very optimistic. We shall see below what opportunities for improvement exist.

The effort in nuclear physics in Yugoslavia has always been balanced between the theoretical and experimental aspects. The "golden days" of Yugoslav experimental nuclear physics were around 1960 , coinciding with the maximum effort in equipment construction. Well known to nuclear physicists are the measurements of total absorption of gamma rays produced in the betatron (JSI, Ljubljana), the investigation of reaction mechanisms and some nucleon problems with $14 \mathrm{MeV}$ neutrons (RBI, Zagreb) and precise measurements in beta spectroscopy (BKI, Vinca). On the theoretical side, the work on the theory of beta decay and nuclear structure calculations of the Zagreb group has met with considerable interest. Activities in high-energy physics, started under favourable auspices in collaboration with CERN, have come to a standstill in recent years*.

Nuclear physics activity in Yugoslavia reached a rather high level in a

\section{Optics and Laser Technology}

international journal of research, design and systems in optics.

Optics and Laser Technology meets the needs of engineers, scientists and technologists interested in optical methods and their applications in science and industry. The journal's aim is to bridge the gap between research and application. It publishes original $\mathbf{R}$ and D papers, applications, articles, critical reviews of new developments, state-of-the-art surveys, news items, patent surveys and conference reports. One-year subscription (four issues) £ 8.00 UK, \& 10.00 (\$ 25.00) overseas, from IPC Science and Technology Press, 32 High Street, Guildford, Surrey, England. very short time and has been slowing down recently. The tremendous increase of the cost of top level research and a general disenchantment with nuclear programmes have not spared Yugoslavia either. It has become clear that Yugoslavia could not support independent large scale nuclear research but should join forces with neighbouring countries. Thus the project of an international regional centre unifying the efforts of several institutions in Northern Italy, Austria, Yugoslavia and Hungary was born. This project, still at a preliminary stage, has met with sympathy amongst politicians in the respective countries. The centre whose approximate cost is estimated at US \$ 1-1.5 million per year should be built on the premises of existing institutions, and its major piece of equipment is to be a $100-\mathrm{MeV}$ variable energy cyclotron.

In comparison with nuclear physics more emphasis was given in the last few years to other fields of physics where closer links with applied research could be foreseen. As a consequence some outstanding contributions to world knowledge were achieved in certain fields of physics of condensed matter, as for instance in :

- theoretical physics of condensed matter (electron gas in metals, quantum liquids, transport phenomena, phase transitions)

- ferroelectrics :

- liquid crystals ;

- physics of metals and alloys :

- magnetic resonance

- neutron scattering.

About 110 scientists have been involved in this research at different interdisciplinary institutes, as well as at university institutes. A regional international centre for solid state physics and molecular sciences is about to be established. At present the following facilities are available among others : NMR, EPR, NQR, double magnetic resonance, spin-echo spectrometers, low temperature facilities, equipment for measuring trans- port co-efficients as well as for the determination of electrical, magnetic and optical properties of matter, electron microscopes etc.

In the past ten years research in the physics of ionized gases has also developed extensively. Investigations of electrical discharges, atomic impact phenomena, interaction of particles and radiation with matter, and dynamics as well as turbulence of plasmas are the most important aspects of this work on which about 100 scientists are engaged at the moment in various research centres.

Clearly, the development of physics in Yugoslavia is now at a stage when more and more high quality results in applied as well as pure research are to be expected. Openminded policies which stimulated the exchange of ideas and personnel, both with western and eastern scientific institutions, greatly helped Yugoslav scientists to reach a high level of professional competence, so that they are now able to find and solve problems of national as well as general interest. The success will, however, largely depend on the funds that will be available in future for research in this field.

- Yugoslavia was a founder member of CERN but ceased to be a full member in 1961 for financial reasons and became instead an Observer. - Editor.

At the Opening Session in Split

(from left to right) Mr. V. Mesko representing the Croatian Ministor of Science, E. Rudberg (Stockholm) President, and N. Cindro (Zagreb) EPS, Vice-Secretary. 
Great activity reigned in the lobby of the largest hotel in Split as numerrous delegates converged on it, some to participate in a conference on European historical cities and others to join the EPS Council Session on 19 and 20 October 1971. 'History' and 'Physics ' were safely separated and channelled into their respective conference rooms. The meetings proceeded smoothly and agreeably thanks to much preparatory work done by Professor N. Cindro, EPS Vice-Secretary, and his aids. Not only did he take good care of the organization but he also acted as host at a pleasant al fresco lunch under palms at his family home outside Split where Venetians and Turks once faced each other across their common frontier.

At the opening session the EPS Council was greeted by Mr. V. Mesko representing the Minister of Science of the Republic of Croatia, who emphasized the important role of the EPS in furthering international relations between physicists in Europe, and the tasks it could perform in helping students in smaller countries and the younger scientists. In thanking him the President confirmed that these were important aims of the Society.

Following the President's review of the activities of the Advisory Committees, W. Martienssen gave an account of the preparations and programme arrangements for the Wiesbaden General Conference. A number of programme modifications were suggested and an appeal was made that

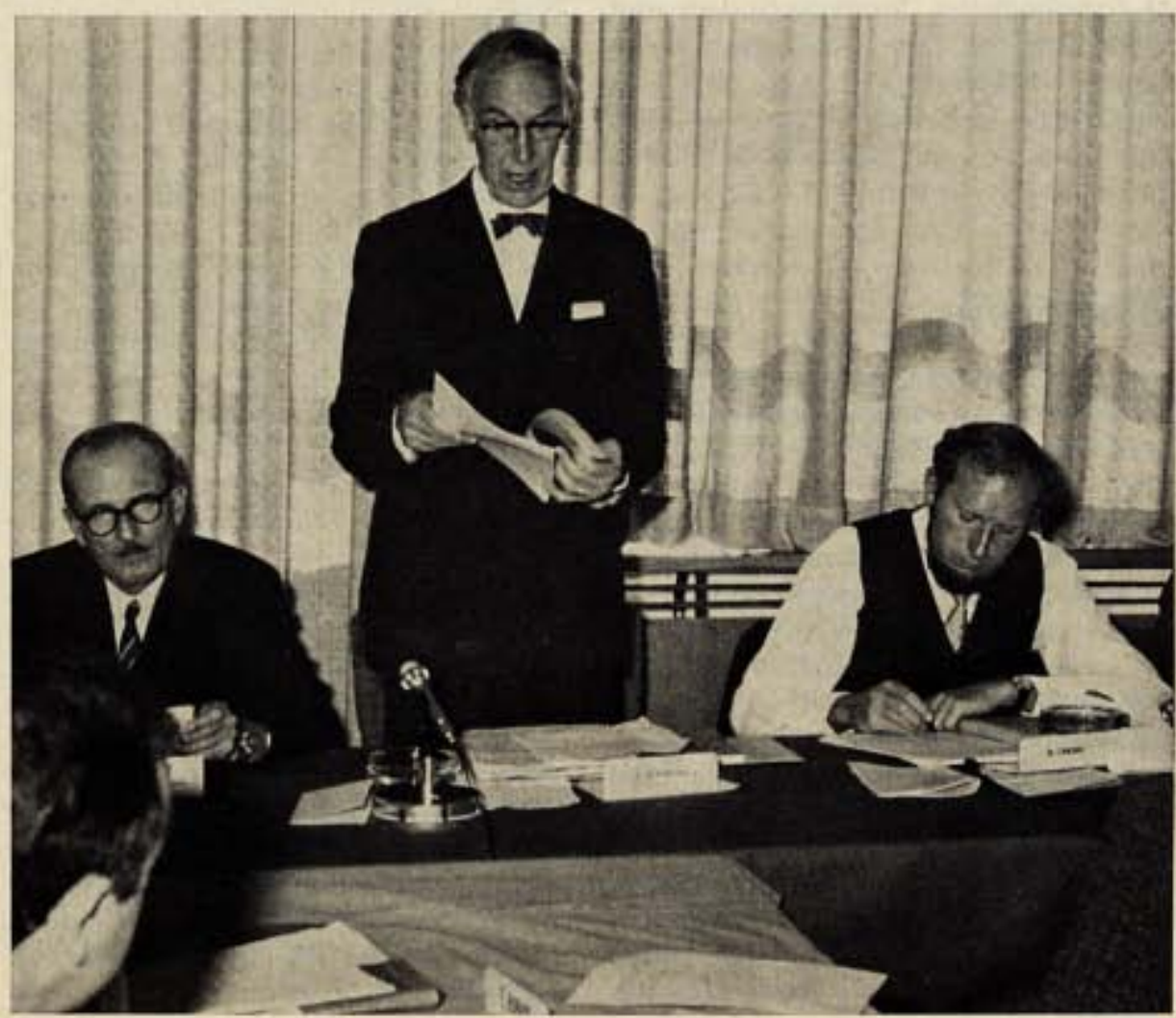

young people should be helped to attend the Conference which, notwithstanding some financial restraints, promises to be an outstanding event in next year's calendar of scientific gatherings.

Financial aspects came again to the fore in the subsequent lively discussion of a report by the Special Administration Study Committee. The operation of the Central Office had been examined so that procedural changes could be suggested which would lead to a reduction in administrative costs. The growth in membership and in the manifold activities of the Society inevitably exerts a mounting pressure on the Main Secretariat. One of the problems is to decide on the priorities regarding the tasks to be performed there within the limits set by the present financial situation. Savings could result from a simplification of the rules for individual membership and in asking the National Societies to take over a larger share of the responsibilities for admission of Individual Ordinary Members, fee collection and distribution of papers. The operation of the Advisory Committees may also

\section{At the Council Session in Split, Yugoslavia}

\author{
W. S. Newman
}

\section{.} cutive terms.

The opportunity for a closer examination of the financial situation came with the presentation of the Auditors' report on the year 1970 and the presentation by the Treasurer of the budgets for 1971 and 1972. After two years in the "red" it was good to find income exceeding expenditure: in effect, for 1971, the provisional positive balance of Sw. Frs 53051 slightly exceeds the figure forecast. Various items of expenditure were discussed in detail and the wish was expressed to increase the contributions to the Divisions. In the budget adopted by Council for 1972 a positive balance of Sw. Frs 22613 is forecast. It remains to be seen whether the target figures for membership and donations can be achieved and what financial consequences will result from the proposed reorganization measures.

After so much discussion of weighty administrative and financial problems it was with some relief that Delegates 